\title{
THE NATURAL HISTORY OF NEPHROSIS
}

\author{
BY \\ R. MCLAREN TODD \\ From the Department of Child Health, University of Liverpool
}

(RECEIVED FOR PUBLICATION SEPTEMBER 7, 1956)

The suffix 'osis' signifies 'a diseased condition' and hence nephrosis means a diseased condition of the kidney (Webster's New International Dictionary). The term nephrosis was used by Müller (1905) to differentiate what he considered degenerative renal disease from other renal conditions to which the term nephritis was applied. He pointed out that hitherto the word nephrosis had been used to describe disorders of the renal pelvis (hydronephrosis, pyonephrosis), but considered that it would be more appropriate to use it for certain diseases of the kidney itself. Volhard and Fahr (1914) classified renal diseases into three groups: (1) Nephroses, in which degenerative lesions were present, with or without amyloidosis; (2) nephritides or inflammatory lesions; and (3) scleroses or arteriosclerotic diseases. Munk (1925) considered that the term nephrosis should be used for all degenerative renal lesions whether of albuminous, fatty, lipoid, necrotic, hyaline, amyloid or glycogen types. Evans (1932) restricted the term nephrosis to those types of Bright's disease which were associated with syphilis or amyloidosis. Allen (1952) used the term nephrosis for either chronic glomerular diseases of the kidney with oedema (lipoid nephrosis) or tubular diseases involving the proximal, distal or both parts of the renal tubules. Fishberg's (1954) conception of nephrosis is of a non-inflammatory disease of the nephron including necrotizing nephrosis, chronic lipoid nephrosis, diabetic glomerulosclerosis (the Kimmelstiel-Wilson syndrome), amyloidosis and toxaemia of pregnancy. By virtue of long usage the term 'pure' nephrosis has been applied to degenerative conditions of the renal tubules caused either by poisons, for example, mercury, lead, arsenic, or by general diseases, for example, syphilis and amyloidosis.

These concepts of nephrosis are based largely upon histological evidence of damage to different parts of the nephron, but to many other writers nephrosis is a clinical rather than a histological entity, a view which has been well summarized by Kramer, Goldman and Cason (1952) in the following terms:

'Nephrosis occupies a position shared by few
diseases in medicine; its aetiology is unknown, its
course unpredictable, its prognosis uncertain and its
treatment unsatisfactory. Nevertheless, its cardinal
manifestations-oedema, hypoproteinaemia, albu-
minuria, hypercholesterolaemia-are so striking,
and the remissions and exacerbations at times so
dramatic as to challenge the attention of both the
clinician and the scientist.'

Ellis (1942) attempted to correlate the clinical features and the histological changes encountered in Bright's disease. His researches, carried out over a 20 -year period at the London Hospital and based upon 370 patients, resulted in the concept of two types of nephritis with dissimilar clinical and histological features. In type 1 Ellis nephritis the illness is of sudden onset, is often preceded by an acute streptococcal throat infection, has haematuria as the most prominent feature and is followed by complete recovery after about six weeks in over $80 \%$ of the patients. Type 2 Ellis nephritis is of insidious onset, is without preceding throat infection, has oedema as the most marked feature and carries a poor prognosis. Confirmation of the views expressed by Ellis has come from many workers including Davson and Platt (1949) who also stated that 'the concept so common in textbooks of oedematous nephritis as a usual intermediate stage between acute and chronic phases is at variance with clinical experience'.

It could be argued that the use of the term nephrosis has confused rather than clarified our knowledge of Bright's disease and to some extent this is true. I would suggest that nephrosis be no longer used when the cause of the renal disturbance is known, as, for example, in amyloid disease, syphilis, mercury poisoning, but that the more appropriate terms such as 'renal amyloidosis' or 'renal syphilitic disease' or 'mercurial tubular degeneration' should be employed. It would seem reasonable to retain the term nephrosis, which is a 
conveniently short word without aetiological connotation, to describe the condition of those patients who have no evidence of amyloidosis, syphilis, diabetic nephrosclerosis, renal vein thrombosis, but who present many of the following features: An illness of insidious onset with the main clinical findings of generalized oedema and pallor; no history of recent throat infection; marked albuminuria, with little or no haematuria; normal blood pressure; lowered plasma protein levels, raised blood cholesterol and normal blood urea concentrations; a prolonged course lasting many months or years.

The use of the word nephritis with division into types 1 and 2 implies that these two conditions are intimately related, whereas the symptoms and signs, the biochemical abnormalities in the blood, treatment, prognosis and histological appearance of the kidneys are so obviously dissimilar.

In medical paediatric practice three main clinical types of renal disease are commonly met: (a) a condition of sudden onset, with haematuria as the most obvious feature, sometimes called type 1 Ellis nephritis but for which I would prefer the descriptive term 'acute (haemorrhagic) nephritis'; (b) an illness having the six main features described above, sometimes called type 2 Ellis nephritis but which I would call 'nephrosis'; and $(c)$ a form of renal disease with increasing evidence of renal insufficiency resulting either from acute nephritis or from nephrosis or following recurrent attacks of pyelonephritis or occurring in association with a congenital renal lesion, which I would call 'chronic nephritis'. The patients reported in this paper were suffering from nephrosis as I have defined it above, and were admitted to Alder Hey Children's Hospital, Liverpool, during the eight-year period 1948 to 1955 inclusive. They were all seen personally during some stage of the illness and have been followed up either in the Out-patient Department or when readmitted to the wards.

Thirty-two patients have been observed, 21 being males and 11 females. The age of onset of the illness is shown in Fig. 1, from which it is apparent

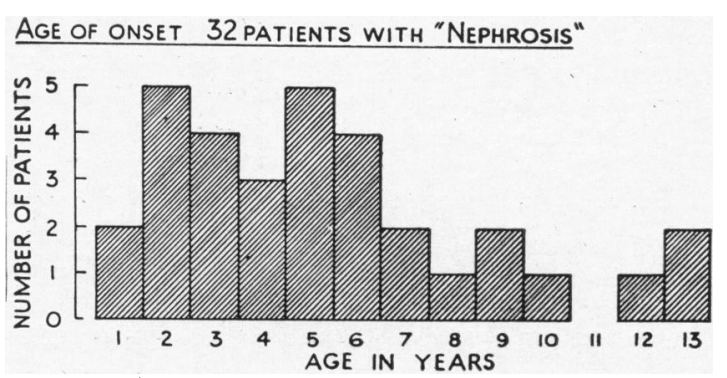

Fro. 1. that $11(34 \%)$ of the patients were under 3 years of age, $14(44 \%)$ between 4 and 7 years, and $7(22 \%)$ over 7 years of age when first seen. A survey of the literature shows that during this eight-year period six large series of patients with nephrosis were reported, and of a total of 349 patients, $228(65 \%)$ were under 3 years of age, $71(20 \%)$ between 4 and 7 years and $50(15 \%)$ over 7 years of age.

\section{Mode of Onset}

The mode of onset was insidious in all patients and there was a period of general ill health varying from a few weeks to several months before the onset of oedema. In a few patients increasing abdominal girth had been noticed. The onset was closely related to the first immunizing injection against diphtheria in one infant aged 7 months, and in another child it was related to the 'booster' diphtheria injection when he was $5 \frac{1}{2}$ years old. I do not know the significance of these observations but it is possible that the onset of the disease in close association with diphtheria immunization was entirely fortuitous. There was no family history of allergic disorders or nephritis in any of the patients.

Clinically the degree of oedema was variable but many patients showed gross generalized oedema when first admitted to hospital. The urine in all patients was loaded with albumin; in a few patients red blood cells were found on microscopical examination, and macroscopic blood was present in two patients for a short period.

\section{Biochemical Investigations}

Biochemical investigations showed that the level of blood urea was below $40 \mathrm{mg}$. \% in 28 of the 32 patients and in the remaining four it showed a temporary elevation. The serum cholesterol values were raised to an average of $470 \mathrm{mg}$. $\%$. The serum protein levels on admission averaged $4.2 \mathrm{~g} . \%$ and the albumin fraction was especially reduced; this led to an alteration of the albumin/globulin ratio from the average normal of 1.25 to 1 to a figure as low as 0.05 to 1 , at which point albumin comprises as little as $5 \%$ of the total protein. The electrophoretic pattern of the globulin fraction was studied in six of the patients, and at the time of their admission to hospital the most striking features were a diminution of the $\gamma$ globulin and an increase in $\alpha_{2}$ globulin. When the electrophoretic pattern is studied in relation to the clinical response of the patient it is apparent that disappearance of oedema and gross albuminuria may precede by many weeks a return to biochemical normality. For example, in one patient the total protein level rose from 
$4 \mathrm{~g} . \%$ to $6 \cdot 1 \mathrm{~g}$. $\%$ over a period of one month, but at this stage the albumin/globulin ratio was still abnormal. During the following six weeks this ratio returned to normal (1.21 to 1$)$. The level of $\gamma$ globulin showed a steady rise but even after nearly three months had not returned to normal; $\alpha_{2}$ globulin was raised initially $(1 \cdot 43 \mathrm{~g} . \%)$ and after nearly three months had fallen to a normal level $(0.84$ g. $\%)$.

\section{Course of the Disease}

The course of the disease could not be predicted on the basis of the history, the clinical features on admission or on the results of the initial biochemical investigations. The duration of the illness varied from three months to five and a half years in

TABLE 1

THE EFFECT OF INFECTIONS UPON OEDEMA

\begin{tabular}{|c|c|c|c|}
\hline Type of Infection & $\begin{array}{c}\text { More } \\
\text { Oedematous }\end{array}$ & $\begin{array}{c}\text { No } \\
\text { Change }\end{array}$ & $\begin{array}{c}\text { Less } \\
\text { Oedematous }\end{array}$ \\
\hline 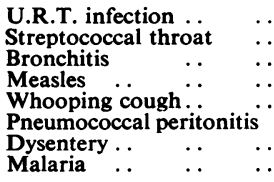 & $\begin{array}{l}4 \\
2 \\
0 \\
0 \\
0 \\
1 \\
1 \\
0\end{array}$ & $\begin{array}{l}3 \\
1 \\
1 \\
1 \\
1 \\
1 \\
2 \\
1\end{array}$ & $\begin{array}{l}1 \\
3 \\
\mathbf{0} \\
\mathbf{3} \\
\mathbf{0} \\
\mathbf{3} \\
\mathbf{1} \\
\mathbf{0}\end{array}$ \\
\hline Total & 8 & 11 & 11 \\
\hline
\end{tabular}

patients who eventually recovered and from six weeks to seven and a half years in those who died (Fig. 2). In many patients the course of the illness was characterized by remissions and exacerbations, and in some instances these variations were related to the development of infections (Table 1). In general terms, acute upper respiratory tract infections were associated with increase in oedema, whereas pneumococcal peritonitis and measles were followed by lessening or disappearance of oedema. In one child there was a complete remission (clinical and biochemical) following measles and this remission lasted for over two years. Barness, Moll and Janeway (1950), reporting upon 161 patients who developed 298 infective episodes, found that infections provoked remis- sions in $25 \%$ of cases, exacerbations in $49 \%$ and no change in $26 \%$.

\section{Treatment}

The many therapeutic measures which have been recommended for patients with nephrosis are eloquent enough testimony to the unsatisfactory nature of the therapy prescribed. Reports advocating a particular form of treatment are published from time to time, but the good results claimed are not easily obtained by other clinicians. The main forms of therapy (Table 2) are designed either to increase

TABLE 2

CHIEF THERAPEUTIC MEASURES USED IN NEPHROSIS

1. Increase plasma proteins
(a) High-protein diet
(b) Intravenous plasma
2. Control oedema
(a) Mechanical-paracentesis (abdominis or thoracis)
(b) Raise colloid osmotic pressure-gum acacia, 'dextran'
(c) Lower extracellular sodium and chloride levels
(d) Renal-merstrict salt intake
- Contreal infections-preventive (streptococci)
3. - curative (pneumococci)
4. By specific infections-measles
5. By hormones-thyroid
6. Morale of parents and patient

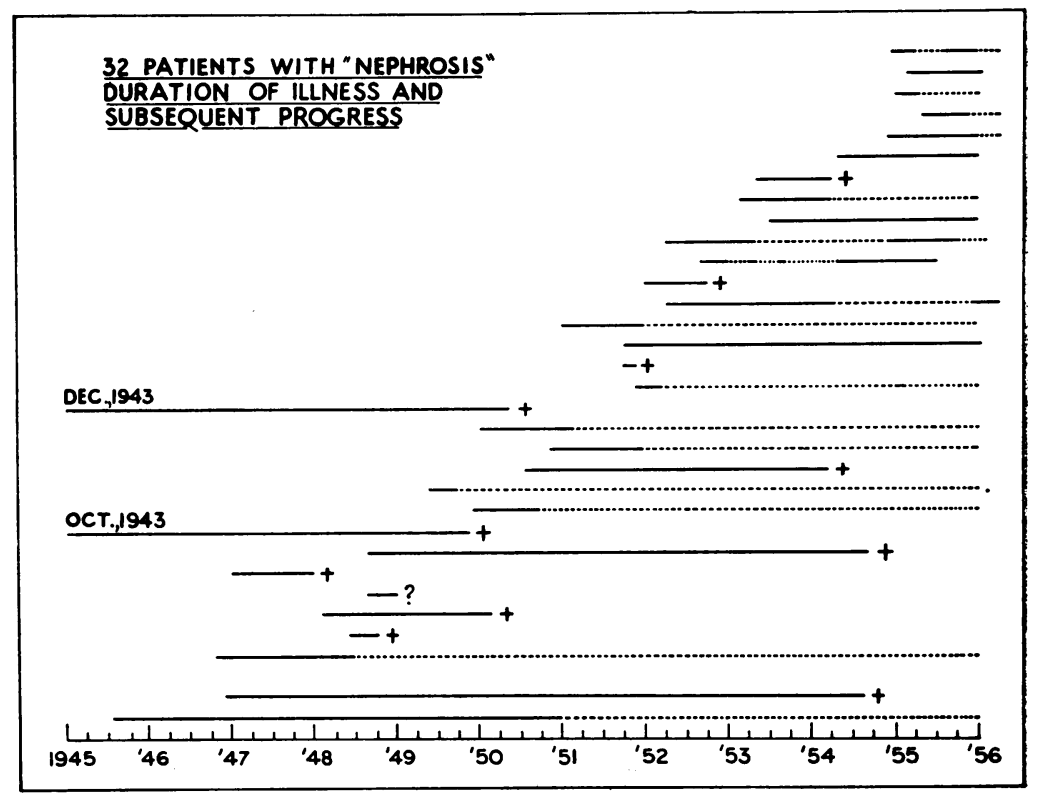

FIG. 2.-Duration of illness of 32 patients with 'nephrosis'.

Continuous line $=$ disease active. $\quad$ Interrupted line $=$ no evidence of activity. 
E.K. (i)

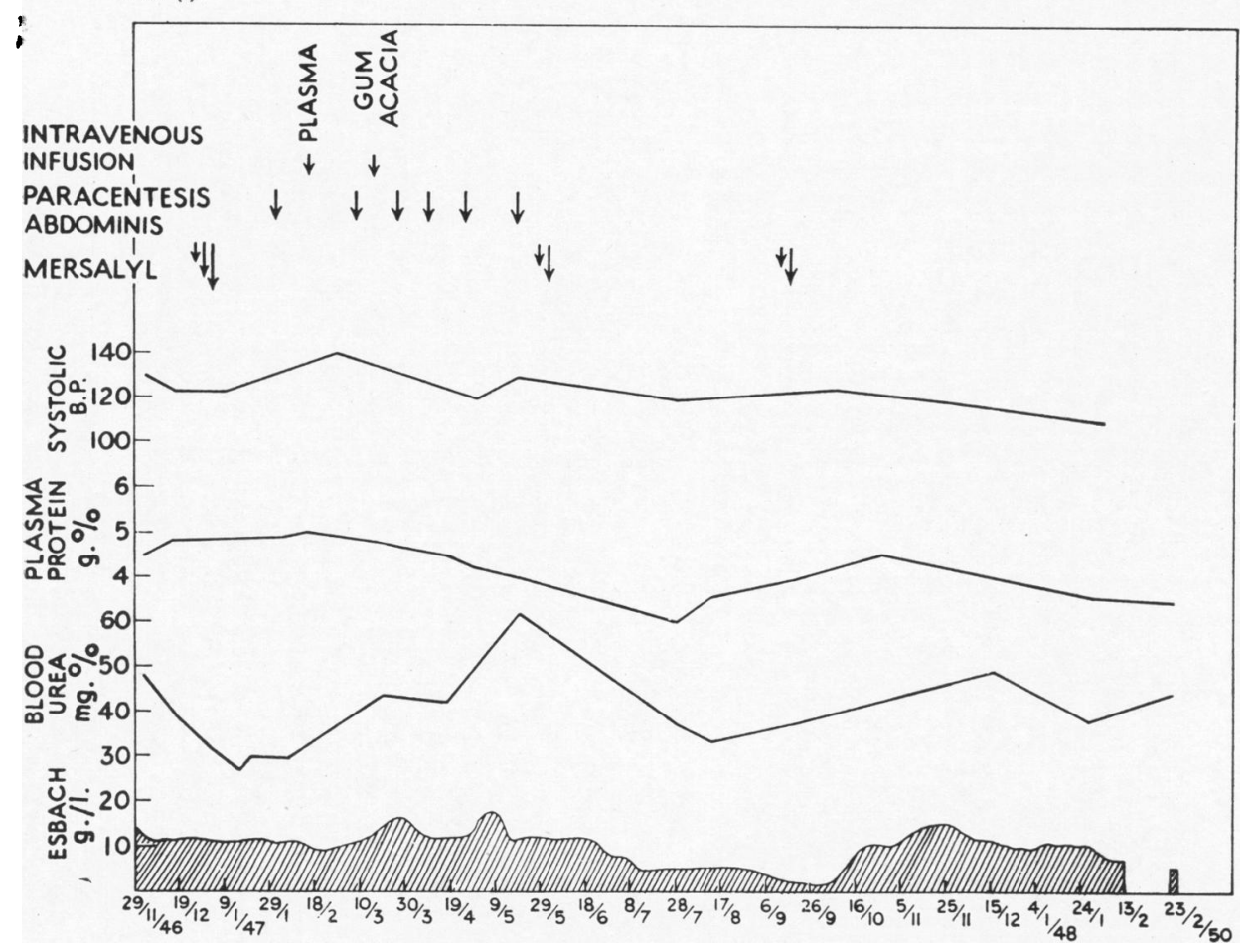

FIG. 3.

E.K. (ii)

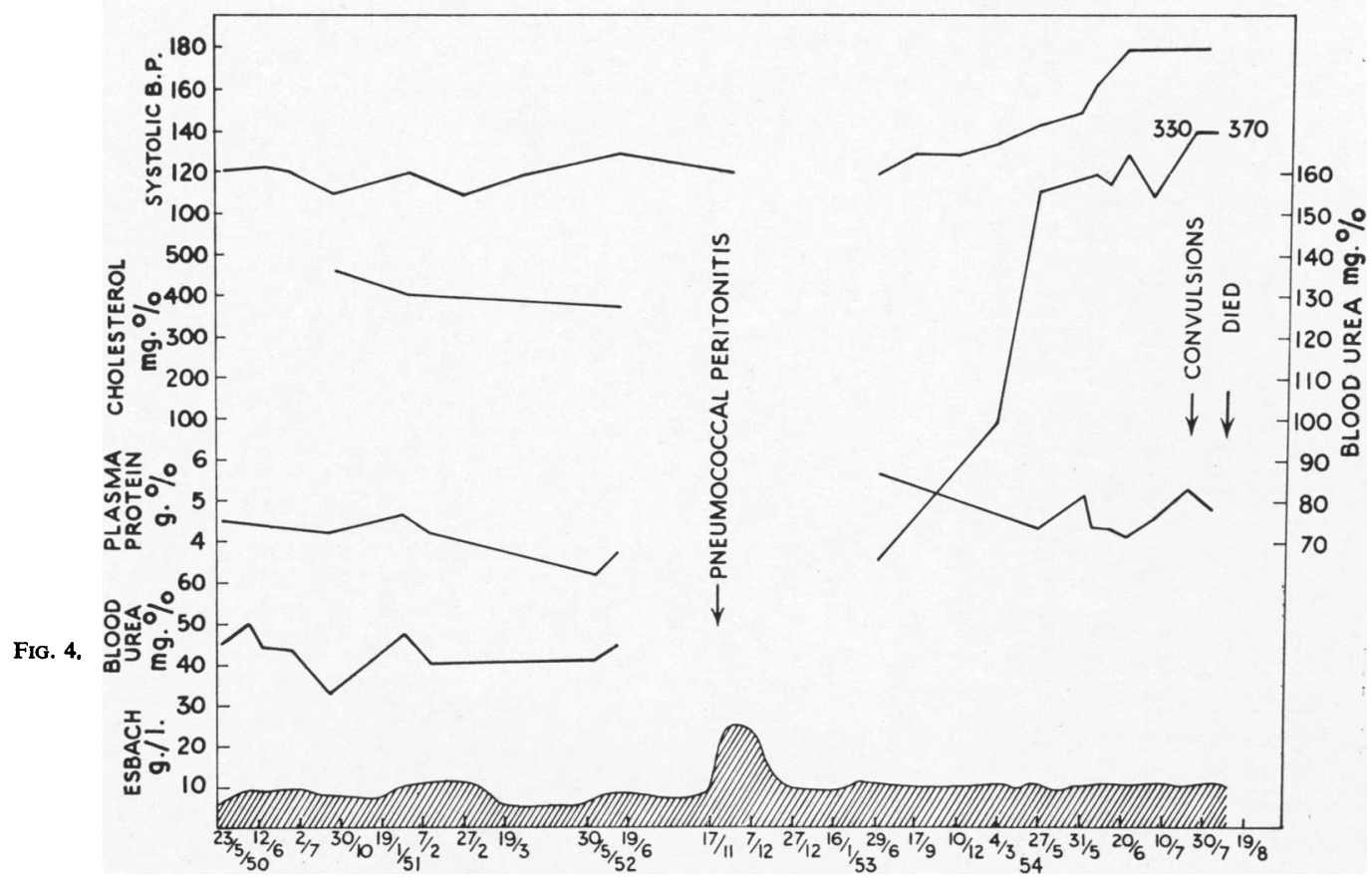

음 
the level of plasma proteins, or to decrease the marked oedema so characteristic of nephrosis, or to control the infections which these patients are so prone to develop. The 32 patients reported here all received a high-protein, low-salt diet, and in addition one or more of the remedies listed in Table 2.

One patient (E.K.), who was seen over an eightyear period, received many of the forms of therapy available before hormones were used (Figs. 3 and 4). $\mathrm{He}$ received a high-protein diet with restriction of sodium intake during the entire eight years, intravenous infusions of plasma and gum acacia, numerous abdominal paracenteses, and mersalyl injections. He developed pneumococcal peritonitis which responded satisfactorily to penicillin therapy after which he lost all the oedema, and he finally died in uraemia after an episode of pericarditis. Unfortunately post-mortem examination was refused so that the macroscopical and microscopical features of the kidneys were not revealed.

The effect of corticotrophin (A.C.T.H.) and cortisone on the natural history of nephrosis has been observed by many workers. In 1951 Luetscher, Deming and Johnson reported the elimination of oedema in 14 patients after treatment with A.C.T.H.; Riley (1952) claimed remissions in 50 patients treated with A.C.T.H. or cortisone; Heymann, Gilkey and Salehar (1955) gave repeated short courses of A.C.T.H. or cortisone lasting 10 to 12 days to 64 children and diuresis occurred in 1,952. The average duration of remissions was $4 \cdot 2$ months after A.C.T.H. and 2.6 months after cortisone. Lange, Slobody and Strang (1955) reported clinical remissions after A.C.T.H. and cortisone but stated that they were short-lived and that recurrences were frequent. Arneil and Wilson (1952, 1953) confirmed the diuretic effect of A.C.T.H. and cortisone but considered that these hormones were of limited value. Four patients in my series of 32 patients were given A.C.T.H. and 13 received cortisone; nine of these 13 patients became less oedematous either during hormone therapy or after it had been discontinued abruptly (Table 3). This response

TABLE 3

EFFECT OF A.C.T.H., CORTISONE AND PREDNISOLONE ON OEDEMA

\begin{tabular}{|c|c|c|c|c|}
\hline & $\begin{array}{c}\text { No } \\
\text { Effect }\end{array}$ & $\begin{array}{l}\text { More } \\
\text { Oedema- } \\
\text { tous }\end{array}$ & $\begin{array}{c}\text { More } \\
\text { Oedema- } \\
\text { tous and } \\
\text { Diuresis } \\
\text { when } \\
\text { Stopped }\end{array}$ & $\begin{array}{l}\text { Less } \\
\text { Oedema- } \\
\text { tous }\end{array}$ \\
\hline $\begin{array}{l}\text { A.C.T.H. (4) } \\
\text { Cortisone (9) } \\
\text { Prednisolone (4) }\end{array}$ & $\begin{array}{l}1 \\
2 \\
-\end{array}$ & $\begin{array}{r}1 \\
2 \\
-\end{array}$ & $\begin{array}{r}1 \\
2 \\
-\end{array}$ & $\begin{array}{l}1 \\
3 \\
4\end{array}$ \\
\hline
\end{tabular}

may be, in part, the result of changes in blood electrolyte concentrations especially involving sodium, but two synthetic cortisone compounds (prednisone and prednisolone) are now available which do not have the marked sodium-retaining activity nor do they provoke the same degree of hypertension as do cortisone or A.C.T.H.

It has been our practice to prescribe a total of $45 \mathrm{mg}$. of prednisolone in divided doses three times daily until the patient is clinically free from oedema. The dose is then reduced by $5 \mathrm{mg}$. every third or fourth day until a maintenance dose of 5 to $10 \mathrm{mg}$.

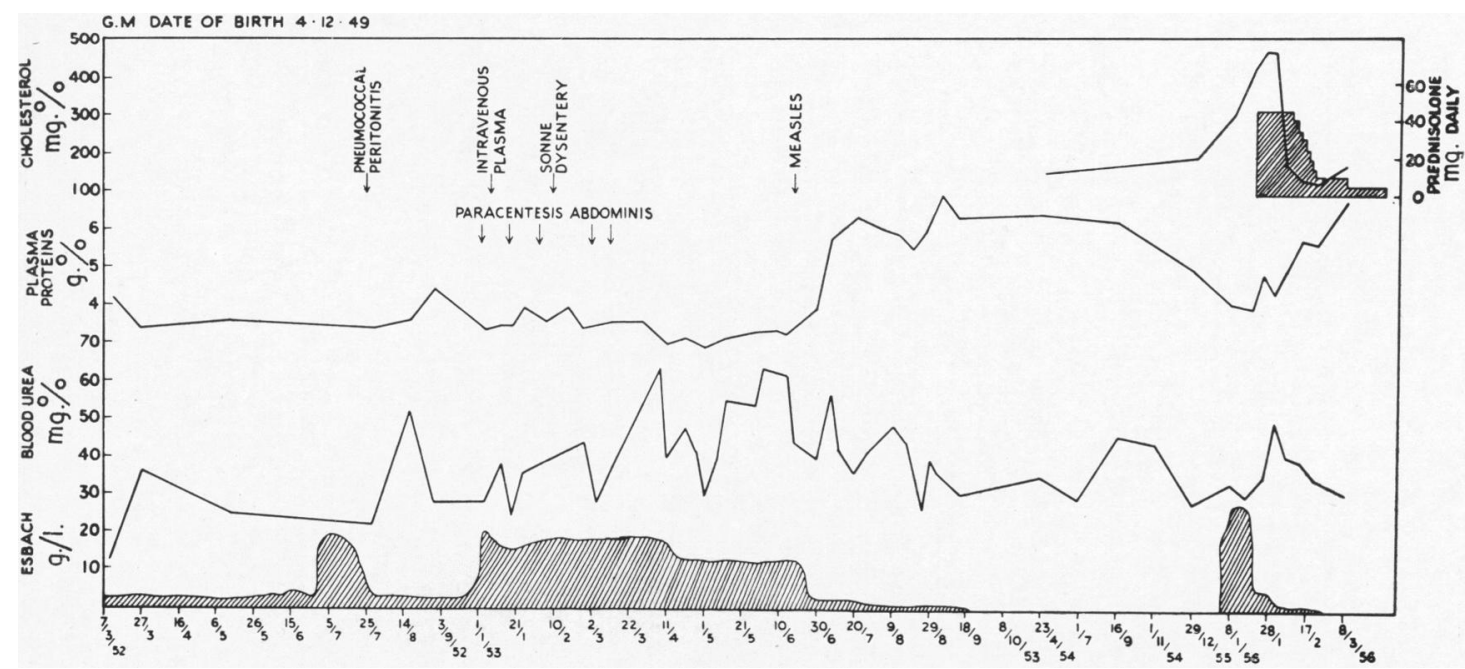

FIG 5. 
is reached. This dose is continued until the biochemical changes, including the protein electrophoretic pattern, have returned to normal.

Fig. 5 illustrates the course of nephrosis in a patient who had a remission which lasted for over two years following measles; after this period he relapsed but marked clinical and biochemical improvement followed therapy with prednisolone.

\section{Results of Therapy}

The fate of these 32 patients is recorded in Table 4 which shows that a third of the patients died, that nearly a third can be considered 'cured' and that a further $15 \%$ are probably cured, although the short follow-up period precludes a definite opinion.

TABLE 4

FATE OF 32 PATIENTS WITH 'NEPHROSIS'

\begin{tabular}{|c|c|c|c|c|c|c|}
\hline \multicolumn{7}{|l|}{ 'Cured' } \\
\hline long-ter & (at least 1 & & $\cdots$ & . & $\cdots$ & 9 \\
\hline short-te & (under 1 , & & $\ldots$ & $\ldots$ & $\ldots$ & 5 \\
\hline Still active & $\ldots$ & $\ldots$ & $\ldots$ & $\ldots$ & $\ldots$ & 6 \\
\hline Died $\quad$. & . & . & $\ldots$ & . & . & 11 \\
\hline Unknown & $\cdots$ & $\ldots$ & $\ldots$ & $\ldots$ & $\ldots$ & 1 \\
\hline
\end{tabular}

In Ellis's original paper the recovery rate in 145 patients was about $5 \%$. A survey of the recent literature suggests that this figure provides too pessimistic a view. In a series of 208 patients published by Barness et al. (1950) $50 \%$ of the patients showed complete recovery when seen two to 23 years after the initial illness. Schwartz, Kohn and Weiner (1943) studied 40 patients for periods up to 20 years and report that $45 \%$ recovered completely. Farr (1943), studying 36 patients reported a recovery rate of $28 \%$, whereas Greenman, Weigand and Danowski (1955) reported that 22 out of 30 patients $(73 \%)$ were entirely normal, but the follow-up period extended only for two years. Rapoport, McCrory and Sohn (1955) studied 40 patients during the years $1949-52$ and $44 \%$ of these had a complete remission, whereas in a further 30 patients studied in 1953 and 1954 complete remissions were reported in $67 \%$ but again in this latter group the follow-up period was only one year.

It appears from these published reports that about $50 \%$ of patients recover completely from this disease. Complete recovery implies absence of oedema and albuminuria and a normal blood chemistry. There are, however, other patients who are symptomless and in whom the blood chemistry is normal, but in whom a trace of urinary albumin persists for many months or years.

\section{Post-mortem Appearances}

Eleven of the patients in my series died and postmortem examination was permitted in seven of them. The macroscopical and microscopical features were of two main types: (a) three patients showed the changes associated with chronic nephritis, and $(b)$ four patients showed the classical features described by Ellis for type 2 nephritis.

(a) These three patients were aged $4 \frac{1}{2}$ years, $8 \frac{1}{2}$ years and 12 years when the first symptoms and signs of illness were apparent, and the illness continued for seven, six and five years respectively. During the last eight to 12 months of life there was evidence of renal insufficiency, with cardiac hypertrophy, increasing hypertension, and markedly raised blood urea level. One child also developed exudates and haemorrhages in the optic fundi. The post-mortem findings were very similar in the three patients; the kidneys were small, contracted and granular, the cortex was ill-defined and the capsule was adherent; microscopically the glomeruli were few and replaced by fibrous tissue, and many of the tubules were dilated.

(b) These four patients developed clinical evidence of nephrosis when aged $1 \frac{1}{2}, 3,5 \frac{1}{2}$ and 12 years old and the duration of the illness was 14 weeks, 12 months, 16 weeks and eight months for the respective patients. None of them showed signs of uraemia, the blood pressure remained within the limits of normal and the blood urea level did not rise above $60 \mathrm{mg} . \%$. Three of the four children had fluid in the pleural and peritoneal cavities from which pneumococci were grown. The kidneys were larger than normal and pale, with well marked differentiation of cortex and medulla. Histologically there was dilatation of the tubules, an increase in the interstitial tissue, tufting of the glomeruli and hyalinization of the basement membrane of the glomeruli.

\section{Summary}

The word 'nephrosis' has been used to describe a variety of renal disorders but in this paper its use is limited to a well defined clinical condition of unknown aetiology, the chief features of which are generalized oedema, heavy albuminuria and lowered plasma proteins.

Thirty-two children with nephrosis have been observed at Alder Hey Children's Hospital, Liverpool, during the eight-year period 1948 to 1955 , and the natural history of the disorder has been studied.

The electrophoretic pattern of plasma proteins has been investigated and characteristic changes in $\gamma$ and $\alpha_{2}$ globulin levels are described. Clinical recovery may precede biochemical recovery and treatment should therefore be continued until the electrophoretic pattern of proteins is normal.

The response to well-established therapeutic measures was disappointing but response of some 
of the patients to hormone therapy and especially to prednisolone has been most encouraging.

Eleven of the 32 patients died, nine can be considered 'cured' and a further five show no clinical abnormalities but the follow-up period is too short to evaluate prognosis.

The post-mortem findings in seven patients are described and were of two main types depending upon the duration of the illness. Four patients with an illness lasting a few months showed the changes described by Ellis for type 2 nephritis, and three patients with an illness lasting several years showed the changes associated with chronic nephritis.

\section{REFERENCES}

Allen, A. C. (1952). The Kidney. London.

Arneil, G. C. and Wilson, H. E. C. (1952). Archives of Disease in Childhood, 27, 322.

- L (1953). Ibid., 28, 372.
Barness, L. A., Moll, G. H. and Janeway, C. A. (1950). Pediatrics, $5,486$.

Davson, J. and Platt, R. (1949). Quart. J. Med., 18, 149.

Ellis, A. (1942). Lancet, 1, 1 .

Evans, G. (1932). In Ball, W. G. and Evans, G., Diseases of the Kidney. London.

Farr, L. E. (1943). Amer, J. Dis, Child. 65, 362.

Fishberg, A. M. (1954). Hypertension and Nephritis, 5th ed. Philadelphia.

Greenman L., Weigand, F. A. and Danowski, T. S. (1955). Amer. J. Dis. Ch hild., 89, 169.

Heymann, W., Gilkey, C. and Salehar, M. (1955). Pediatrics, 15, 49. Kramer, B., Goldman, H. and Cason, L. (1952). J. Pediat., 41, 792 Lange, K., Slobody, L. and Strang, R. (1955). Pediatrics, 15, 156. Luetscher, J. A Deming, Q. B. and Johnson, B. B. (1951). J. clin. Luetscher, J. A., Deming,

Müller, F. (1905). Verhandlungen der deutschen Pathologischen Gesellschaft Meran, pp. 64-99.

Munk, F. (1925). Pathologie und Klinik der Nierenerkrankungen, pp. 185-364. Berlin.

Rapoport, M., McCrory, W. and Sohn, W. (1955). Amer. J. Dis. Child., 90, 631.

Riley, C. M.' (1952). J. Amer. med. Ass., 150, 1288.

Schwarz, H., Kohn, J. L. and Weiner, S. B. (1943). Amer. J. Dis. Child., 65, 355 .

Volhard, F. and Fahr, T. (1914). Die Brightsche Nierenkrankheit. Berlin. 